\title{
Calculation of CO Behavior in the Platform for Deeply Underground Subway Station with Different Fire Strengths
}

\author{
Yong-Jun Jang, Ji-Min Ryu, Jong-Ki Kim, Min-Chul Chun and Dong-Hoe Koo \\ Railroad Safety Center, Korea Railroad Research Institute, Gyeonggi-do 437-757, South Korea
}

Received: January 18, 2016 / Accepted: February 02, 2016 / Published: March 31, 2016.

\begin{abstract}
Effect of different fire strengths on the smoke distribution in the subway station is investigated. Shin-Gum-Ho station (line \#5) in Seoul is selected as a case study for variation of CO (carbon monoxide) distribution caused by the fire in the platform. The ventilation in the station is set to be an air supply mod in the lobby and an air exhaustion mod in the platform. One-side main tunnel ventilation $\left(7,000 \mathrm{~m}^{3} / \mathrm{min}\right)$ is applied to operate in the tunnel. The fire is assumed to break out in the middle of train parked in the platform tunnel. Two kinds of fire strength are used. One is $10 \mathrm{MW}$ and the other is $20 \mathrm{MW}$. Ventilation diffusers in the station are modeled as 317 square shapes \& four rectangular shapes in the lobby and platform. The total of 7.5 million grids is generated and whole domain is divided to 22 blocks for parallel computation. Large eddy simulation method is applied to solve the momentum equation. The behavior of $\mathrm{CO}$ is calculated according to different fire strengths and compared with each other.
\end{abstract}

Key words: Carbon monoxide, subway station, fire strength, main tunnel ventilation, LES.

\section{Introduction}

Korea government has steadily supported the fire-accident prevention research since fire disaster in Daegu subway station which occurred in 2003. It has enforced to establish the several laws for fire safety standard in railway system in Korea. However, the fire-safety measures for subway station and subway tunnel have not been much arranged yet in Korea.

Some researchers have studied the fire-driven flow analysis in tunnel. Hwang and Edwards [1] studied the hot stratified flow and ventilated flow in tunnel. Hwang and Wargo [2] showed the thermally generated reverse stratified layers in fire tunnel using experimental method. Jang, et al. [3] studied the back-layer flow phenomena in the straight tunnel using LES (large eddy simulation) and RANS (Reynolds-averaged Navier-Stokes). They compared the simulated results with experimental data and

Corresponding author: Yong-Jun Jang, principal researcher, research field: thermo-fluid dynamics in railway. showed that LES produced better results than RANS. Fletcher, et al. [4] experimentally investigated the tunnel fire using a pool fire. They also calculated the same fire-driven flow as their experiments using $k-\varepsilon$ model and compared the results. Gao, et al. [5] theoretically studied the tunnel fire flow which was experimentally done by Fletcher, et al. [4]. They employed LES method and compared the results with experimental data. Jang, et al. [6] experimentally investigated the ordinary and emergency ventilation system in deeply underground subway station to study the exact ventilation capacity of subway station. Jang, et al. [7] analyzed the smoke distribution in the subway station with various main tunnel ventilations. They showed the smoke density was reduced in the platform of station with main tunnel ventilation.

Effect of fire strength on the smoke distribution in the subway station is investigated in this research. Shin-Gum-Ho subway station (depth: $46 \mathrm{~m}$ ), which is the same station as studied by Jang, et al. [7], is 
Table 1 Case study for different fire strengths.

\begin{tabular}{|c|c|c|c|}
\hline Cases & Descriptions & $\begin{array}{l}\text { Tunnel ventilation } \\
\text { capacity }\end{array}$ & $\begin{array}{l}\text { Fire } \\
\text { strength }\end{array}$ \\
\hline 1 & $\begin{array}{l}\text { No main tunnel } \\
\text { ventilation }\end{array}$ & 0 & $10 \mathrm{MW}$ \\
\hline 2 & One side exhaustion & $-7,000 \mathrm{~m}^{3} / \mathrm{min}$ & $10 \mathrm{MW}$ \\
\hline 3 & $\begin{array}{l}\text { No main tunnel } \\
\text { ventilation }\end{array}$ & 0 & $20 \mathrm{MW}$ \\
\hline 4 & One side exhaustion & $-7,000 \mathrm{~m}^{3} / \mathrm{min}$ & $20 \mathrm{MW}$ \\
\hline
\end{tabular}

selected as a case study for variation of CO (carbon monoxide) distribution caused by the different fire strengths. The $\mathrm{CO}$ density is most concerned when fire break out in subway station.

Fire is assumed to break out in the middle of train which is parked in platform. The two kinds of fire strength are used. One is $10 \mathrm{MW}$ and the other is $20 \mathrm{MW}$. Currently, ventilation operation mode in Shin-Gum-Ho station is set up as a full exhaustion mode in the platform in case of platform-fire emergency. Furthermore, main tunnel ventilation is also applied to be operated as prescribed in Table 1 for helping of smoke exhaustion in platform. The LES method in FDS (fire dynamics simulator) code is used to simulate the fire-driven flow in this station. Parallel computation is employed to reduce the calculation time.

\section{Modeling of Station}

The total number of floors in Shin-Gum-Ho station is 8 . The first and second floor undergrounds are lobby and the eighth floor underground is platform. Fig. 1 shows the overall view and ventilation

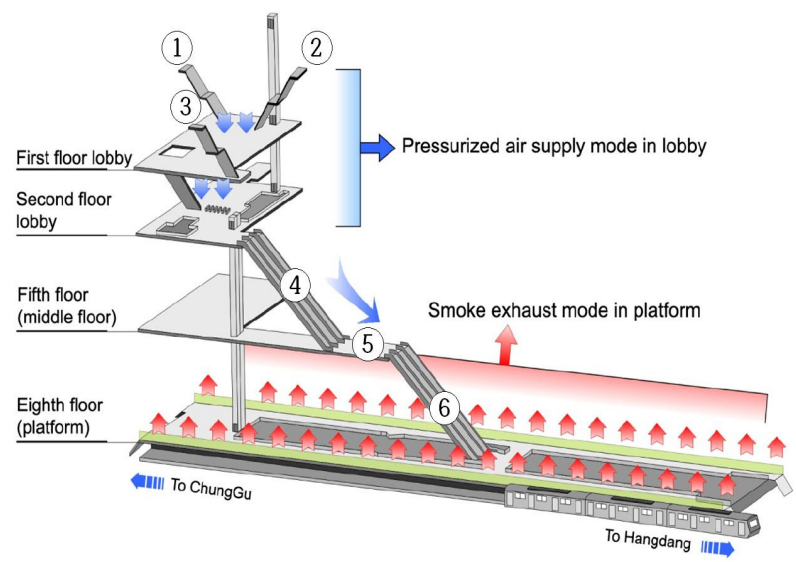

Fig. 1 Ventilation fan modes in Shin-Gum-Ho station for emergency state.
Table 2 Ventilation rate in the lobby and platform of Shin-Gum-Ho station for emergency state.

\begin{tabular}{llll}
\hline \multirow{2}{*}{ Case } & \multicolumn{3}{l}{ Flow rate $\left(\mathrm{m}^{3} / \mathrm{h}\right)$} \\
\cline { 2 - 4 } $\begin{array}{lll}\text { Emergency } \\
\text { state }\end{array}$ & Lobby & Supply air & Exhaustion \\
\hline & Platform & - & $-22,561$ \\
Ony & & \\
\hline
\end{tabular}

(a) No main tunnel ventilation

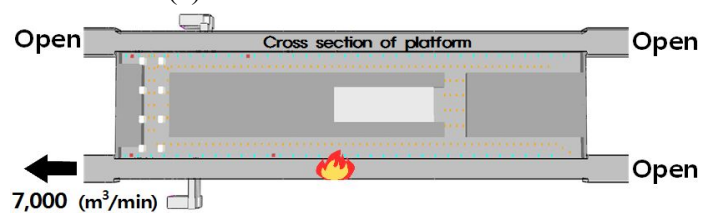

(b) Main tunnel ventilation $\left(7,000 \mathrm{~m}^{3} / \mathrm{min}\right)$

Fig. 2 Application of main tunnel ventilation.

condition for emergency state in Shin-Gum-Ho station. The pressurized air is supplied in the first and second floor lobby. The contaminated air by smoke in the platform is exhausted through the ventilation. Table 2 [6] shows the ventilation rate in the lobby and platform of Shin-Gum-Ho station for emergency state.

Fig. 2 shows the conditions for main tunnel ventilation and capacity which is well described in Table 1. Fig. 3 shows the ventilation distribution in the first and second floor underground. Ventilation diffusers are modeled as 95 square shapes of $0.6 \mathrm{~m}(\mathrm{x}) \times 0.6 \mathrm{~m}(\mathrm{y})$ in the lobby (Fig. 3) and as 222 square shapes of $0.6 \mathrm{~m}(\mathrm{x}) \times 0.6 \mathrm{~m}(\mathrm{y})$ and four large rectangular shapes of $1.2 \mathrm{~m}(\mathrm{x}) \times 0.8 \mathrm{~m}(\mathrm{y})$ in the platform (Fig. 4).

\section{Governing Equation and Numerical Methods}

The FDS code solves numerically a form of Navier-Stokes equations, and the core algorithm for momentum equations is an explicit predictor-corrector scheme that uses second order accurate finite-difference approximation. The flow variables are updated in time using an explicit second-order Runge-Kutta scheme. Turbulence is treated by means of the Smagorinsky form of LES. 


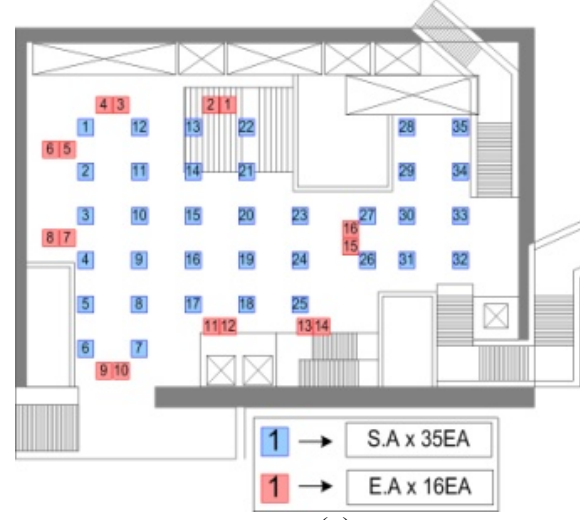

(a)

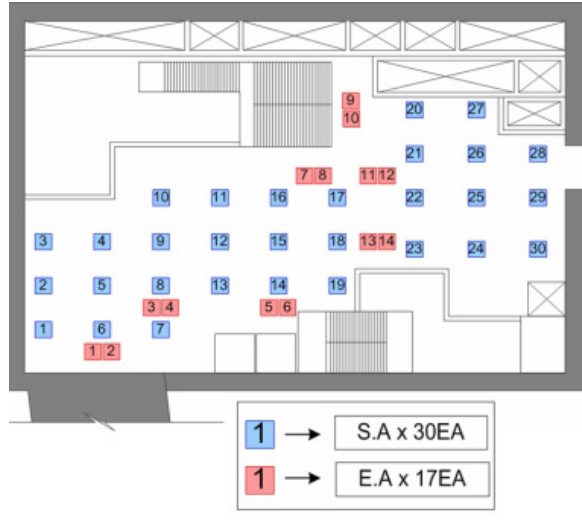

(b)

Fig. 3 Diffuser arrangement of (a) the first floor underground and (b) the second floor underground.

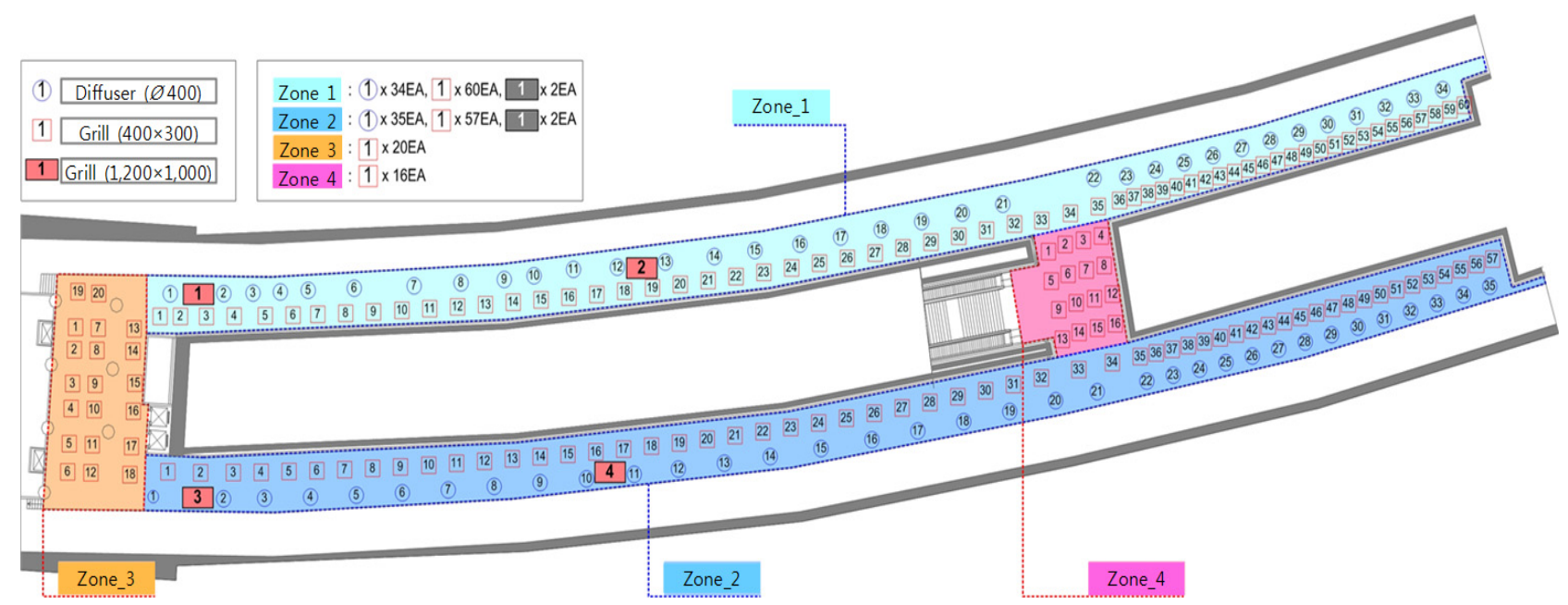

Fig. 4 Diffuser arrangement in the platform of Shin-Gum-Ho station.

The governing equations [8] for LES in FDS are as follows:

$$
\begin{gathered}
\frac{D \overline{U_{i}}}{D t}=-\frac{1}{\rho} \frac{\partial \bar{P}}{\partial x_{i}}+\frac{\partial}{\partial x_{j}}\left\{v\left(\frac{\partial \overline{U_{i}}}{\partial x_{j}}+\frac{\partial \overline{U_{j}}}{\partial x_{i}}\right)-\tau_{i j}\right\} \\
\tau_{i j}=\overline{U_{i} U_{j}}-\overline{U_{i} \overline{U_{j}}} \\
\tau_{i j}-\frac{1}{3} \delta_{i j} \tau_{k k}=-2 v_{t} \overline{S_{i j}} \\
\overline{S_{i j}}=\frac{1}{2}\left(\frac{\partial \overline{U_{i}}}{\partial x_{j}}+\frac{\partial \overline{U_{j}}}{\partial x_{i}}\right)
\end{gathered}
$$

In Eqs. (1)-(4), $\rho, \bar{P}, \overline{U_{i}}, \tau_{i j}, \overline{S_{i j}}$ and $v_{t}$, respectively denotes density, mean static pressure, mean velocity, turbulent fluctuation tensor, strain rate tensor and turbulent viscosity.
Where $v_{t}$ should be modeled, Smagorinsky model [9] is employed in FDS code.

$$
\begin{aligned}
& v_{t}=\left(C_{s} \bar{\Delta}\right)^{2}|\bar{S}| \\
& |\bar{S}|=\left(2 S_{i j} S_{i j}\right)^{1 / 2} \\
& \bar{\Delta}=(\Delta x \Delta y \Delta z)^{1 / 3}
\end{aligned}
$$

where, $C_{s}$ is an empirical constant and is 0.2. In Eq. (7),

$\Delta x, \Delta y, \Delta z$ denote grid distances in $\mathrm{x}, \mathrm{y}, \mathrm{z}$ coordinates, respectively.

The grid size is then selected to be $0.2 \mathrm{~m}$ and the total grid numbers are 7.5 million (Fig. 5). The whole domain is divided to 22 blocks and computed on 10 CPU (central processing unit) in parallel using MPI (message passing interface). 


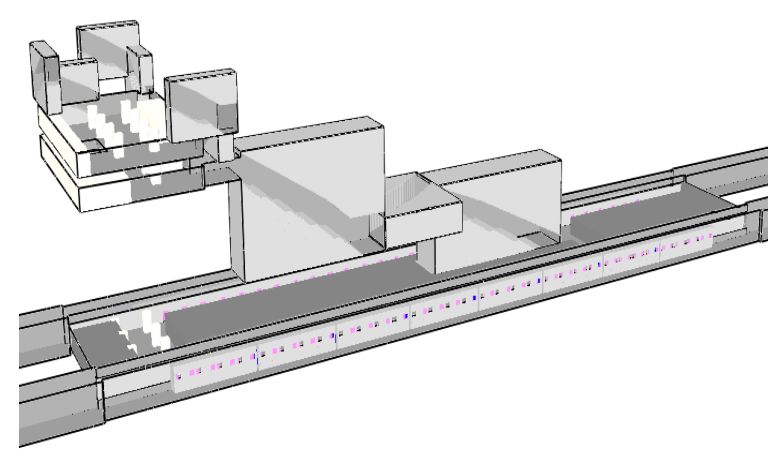

Fig. 5 Grid modeling for Shin-Gum-Ho subway station.

\section{Results and Discussion}

Fig. 6 shows velocity vectors (maximum $\approx 0.97 \mathrm{~m} / \mathrm{s}$ ) in the entrance region (4) in Fig. 1) and middle floor region (5) in Fig. 1) of the stairway for fire strength $10 \mathrm{MW}$ without main tunnel ventilation at $1,300-1,500 \mathrm{~s}$. The fresh air in the lobby is moving down through the stairway to the platform. It is observed that, the hot smoke air due to the fire in the platform cannot overcome the incoming flow from the lobby. Therefore, $\mathrm{CO}$ cannot move up to the lobby with fire strength $10 \mathrm{MW}$ in the platform. Fig. 7 shows velocity vectors in the same locations as in Fig. 6 with main tunnel ventilation $\left(7,000 \mathrm{~m}^{3} / \mathrm{min}\right)$. The velocity vectors (maximum $\approx 2.2 \mathrm{~m} / \mathrm{s}$ ) in the stairway become stronger than without main tunnel ventilation. The reason is that, the pressure in the platform is decreased due to the operation of tunnel ventilation. Large vortices are found in the stairway and its size is about $1.5 \mathrm{~m}$ in height. Fig 8 shows velocity vectors (maximum $\approx 1.12 \mathrm{~m} / \mathrm{s}$ ) in the same locations as in Fig. 6 for fire strength $20 \mathrm{MW}$ without main tunnel ventilation. The magnitude of velocity is similar with case of $10 \mathrm{MW}$. The back flow is slightly generated near the top of middle floor because of buoyancy force of smoke caused by stronger fire strength in the platform. Fig 9 shows velocity vectors (maximum $\approx 2.3 \mathrm{~m} / \mathrm{s}$ ) in the same locations as in Fig. 6 with fire strength $20 \mathrm{MW}$ and with main tunnel ventilation $\left(7,000 \mathrm{~m}^{3} / \mathrm{min}\right)$. The magnitude of velocity is increased compared with no main tunnel ventilation, however, is similar with Case 2.



(a)

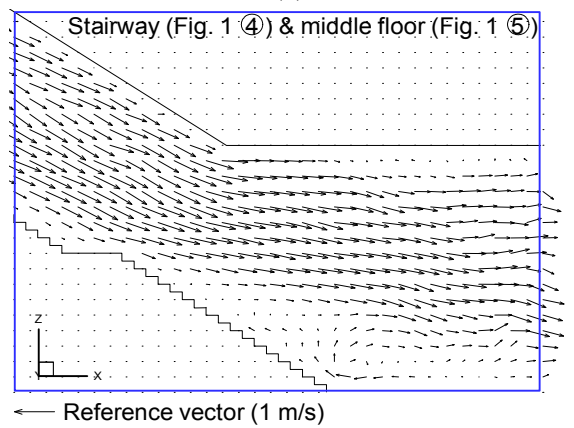

(b)

Fig. 6 Velocity vectors (every other vector) in the stairway: (a) entrance region and (b) middle floor region for $10 \mathrm{MW}$ without tunnel ventilation.

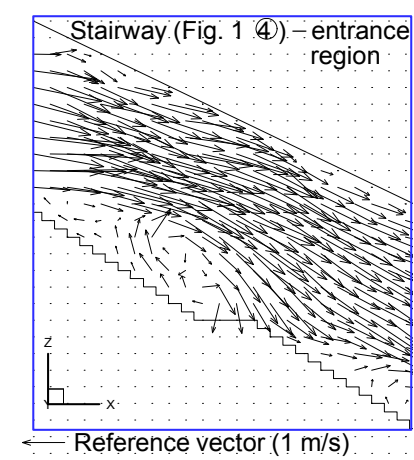

(a)

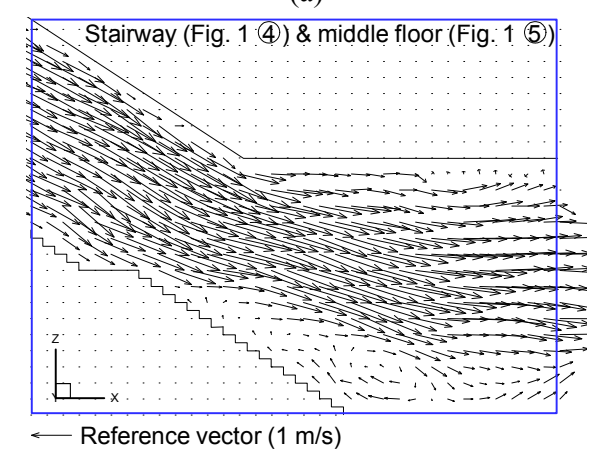

(b)

Fig. 7 Velocity vectors (every other vector) in the stairway: (a) entrance region and (b) middle floor region for $10 \mathrm{MW}$ with tunnel ventilation. 

Station with Different Fire Strengths

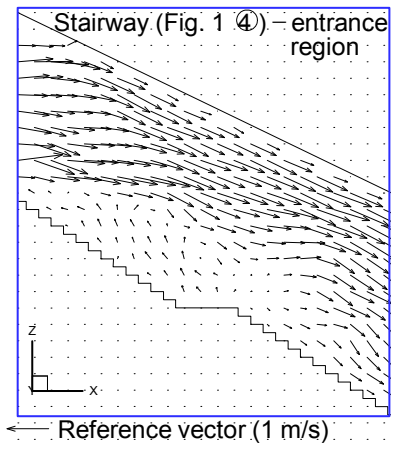

(a)

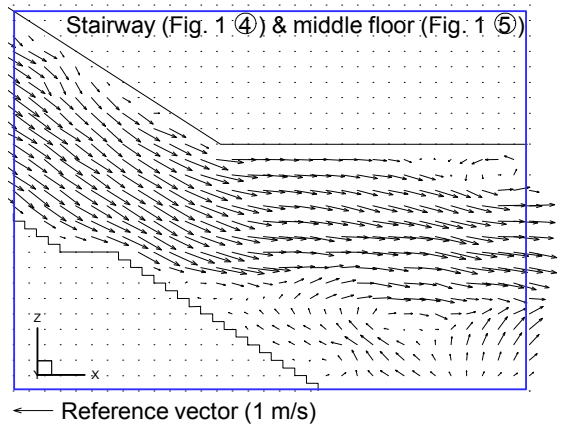

(b)

Fig. 8 Velocity vectors (every other vector) in the stairway: (a) entrance region and (b) middle floor region for $20 \mathrm{MW}$ without tunnel ventilation.

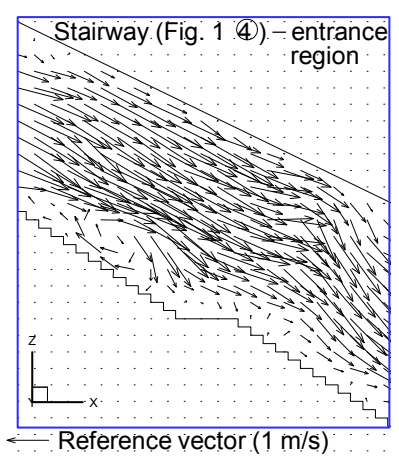

(a)

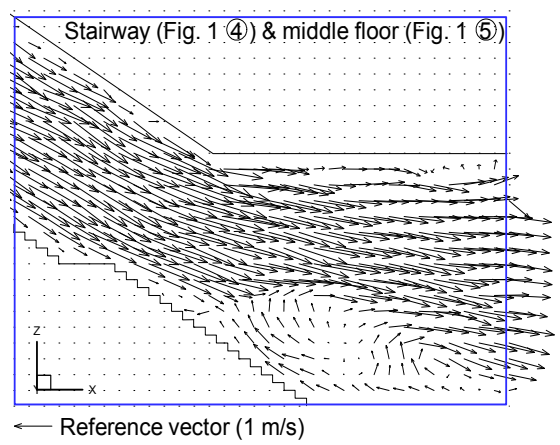

(b)

Fig. 9 Velocity vectors (every other vector) in the stairway: (a) entrance region and (b) middle floor region for $20 \mathrm{MW}$ with tunnel ventilation.
Fig. 10 shows the soot (smoke) distribution in the platform. Large amounts of soot occupy the platform without main tunnel ventilation (Figs. 10a and 10c). In
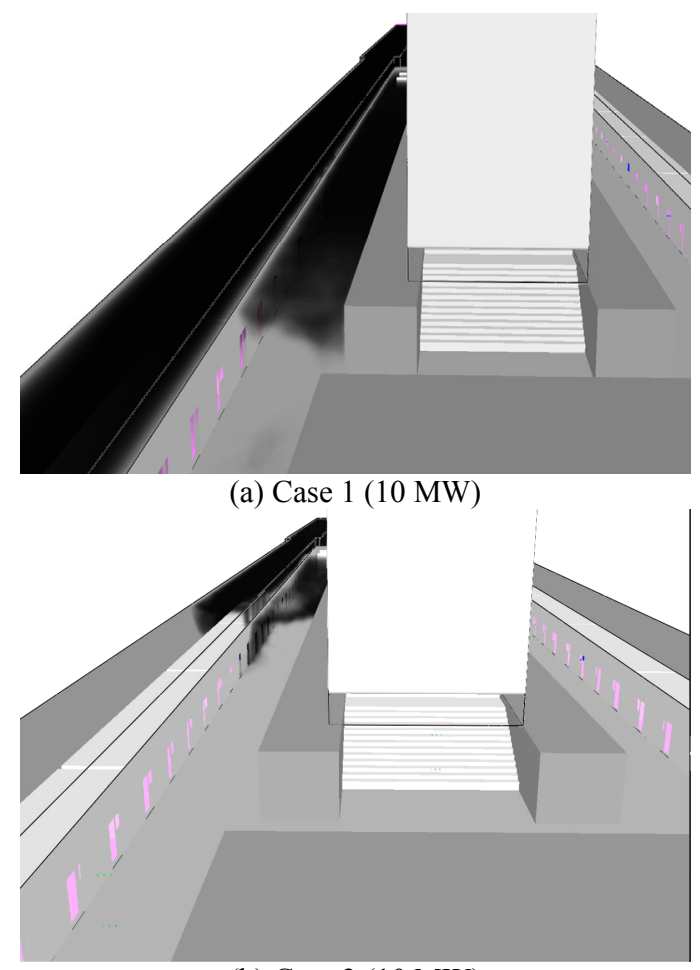

(b) Case 2 (10 MW)

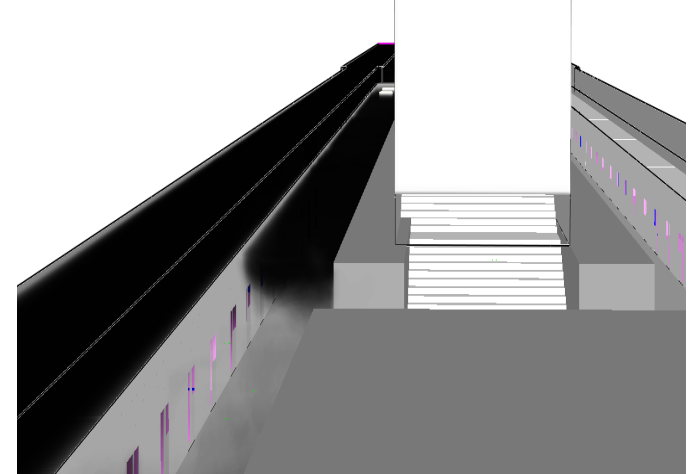

(c) Case 3 (20 MW)

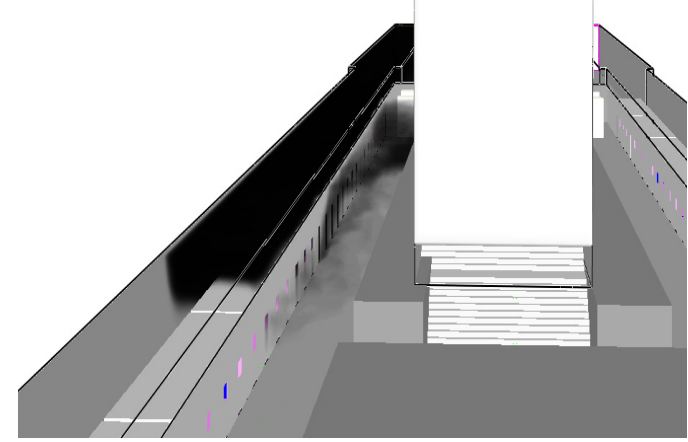

(d) Case 4 (20 MW)

Fig. 10 Soot distributions in the platform with different fire strengths. 


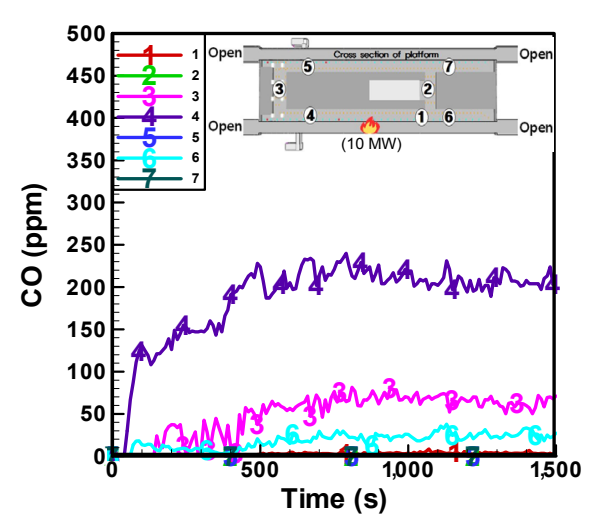

(a) Case 1 (10 MW)

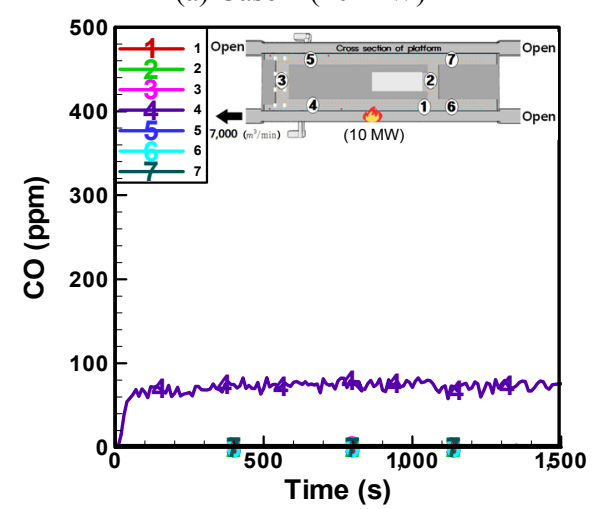

(b) Case $2(10 \mathrm{MW})$

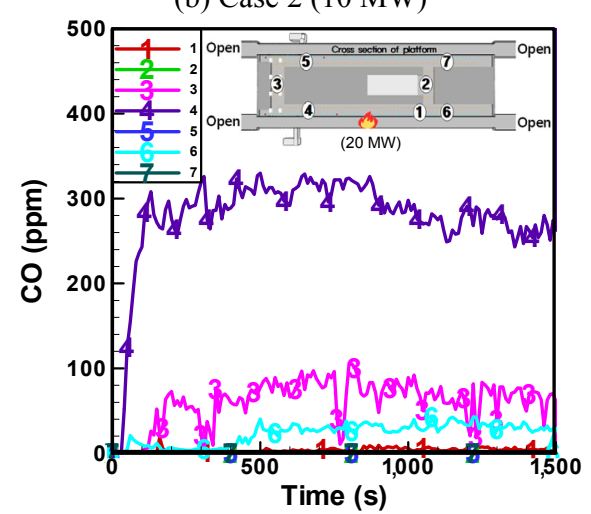

(c) Case3 (20 MW)

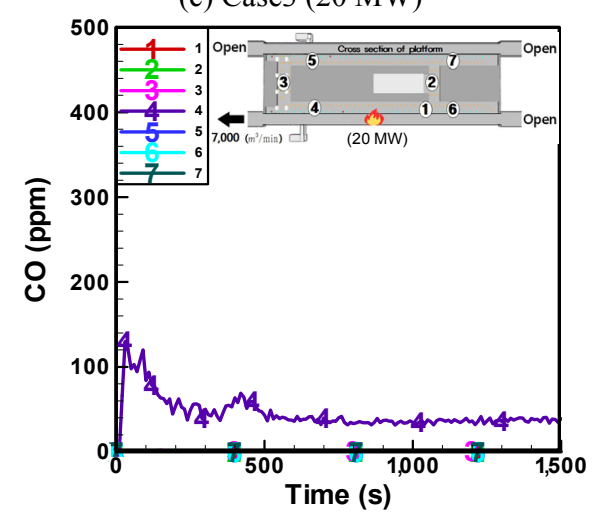

(d) Case 4 (20 MW)

Fig. 11 Calculated $\mathrm{CO}$ in the platform with different fire strengths. case of operation of main tunnel ventilation, the smoke is not much propagated into the platform due to the tunnel ventilation (Figs. 10c and 10d). However, the soot is a little more propagated into the platform with $20 \mathrm{MW}$ than with $10 \mathrm{MW}$. It is clearly seen that, the main tunnel ventilation plays an important role to eliminate the smoke in the platform and help the passenger escape to safety zone.

Fig. 11 shows $\mathrm{CO}$ distribution in the platform with different fire strengths. The $\mathrm{CO}$ densities are calculated at seven points in the platform. The soot density is $50 \%$ increased with stronger fire strength $20 \mathrm{MW}$ in the platform. With main tunnel ventilation, however, the soot is decreased by $65 \%-80 \%$. Interesting thing is the soot density has become steady state after $1,000 \mathrm{~s}$ since fire occurrence in both $10 \mathrm{MW}$ and $20 \mathrm{MW}$ case. It seems that, the steady state circumstance is dependent on total ventilation capacity in the station and tunnel.

\section{Conclusions and Summary}

$\mathrm{CO}$ distributions generated by the fire in the platform with different fire strengths in the subway station are calculated. The Shin-Gum-Ho station in the Seoul is modeled. The smoke flow due to the fire is analyzed and then the distribution of $\mathrm{CO}$ is calculated. LES and parallel computing is employed to simulate the fire-driven flow in the whole station.

The flow in the stairway and middle floor goes down to the platform due to the low pressure caused by strong ceiling ventilation in the platform. Main tunnel ventilation induces much increased going-down flow in the stairway. With fire strength $10 \mathrm{MW}$ in the platform, the velocity in the stairway is about $0.9 \mathrm{~m} / \mathrm{s}$ or less. With fire strength $20 \mathrm{MW}$ in the platform, the velocity in the stairway is about $1.1 \mathrm{~m} / \mathrm{s}$ which is similar with $10 \mathrm{MW}$ case. The back flow is slightly generated near the top of middle floor because of buoyancy force with fire strength $20 \mathrm{MW}$. The magnitude of velocity in the stairway with main tunnel ventilation is two times larger than without 


\section{Station with Different Fire Strengths}

tunnel ventilation. The soot density is $50 \%$ increased with stronger fire strength $20 \mathrm{MW}$ in the platform. With main tunnel ventilation, however, the soot is decreased by $65 \%-80 \%$.

\section{Acknowledgment}

This research is supported by a grant (PK1606C9) from Korea Railroad Research Institute.

\section{References}

[1] Hwang, C. C., and Edwards, J. C. 2005. "The Critical Ventilation Velocity in Tunnel Fires-A Computer Simulation." Fire Safety Journal 40 (3): 213-44.

[2] Hwang, C. C., and Wargo, J. D. 1986. "Experimental Study of Thermally Generated Reverse Stratified Layers in a Fire Tunnel." Combustion and Flame 66 (2): 171-80.

[3] Jang, Y. J., Kim, H. B., Kim J. H., and Han, H. Y. 2009. "Comparative Study on the Numerical Simulation for the Bake-Layer of The Tunnel Fire-Driven Flow with LES and RANS." Transactions of the KSME (B) 33 (3): 156-63.
[4] Fletcher, D. F., Kent, J. H., and Apte, V. B. 1994. "Numerical Simulations of Smoke Movement from a Pool Fire in a Ventilated Tunnel." Fire Safety Journal 23 (4): 305-25.

[5] Gao, P. Z., Liu, S. L., Chow, W. K., and Fong, N. K. 2004. "Large Eddy Simulation for Studying Tunnel Smoke Ventilation." Tunneling and Underground Space Technology 19 (6): 577-86.

[6] Jang, Y. J., Lee, H. S., and Park, D. S. 2012. "Experimental Study for the Capacity of Ordinary and Emergency Ventilation System in Deeply Underground Subway Station." Journal of the Korean Society for Railway 15 (6): 579-87.

[7] Jang, Y. J., Ryu, J. M., Park, S. H., and Koo, D. H. 2015. "Analysis of Smoke Distribution in the Subway Station with Various Main Tunnel Ventilations." Journal of Energy and Power Engineering 9 (4): 405-10.

[8] McGrattan, K., McDermontt, R., Hostikka, S., and Floyd, J. 2010. Fire Dynamics Simulator (Ver. 5) User's Guide. Washington: NIST (National Institute of Standards and Technology).

[9] Smagorinsky, J. 1963. "General Circulation Experiments with the Primitive Equation-I. The Basic Experiment." Monthly Weather Review 91 (3): 99-164. 